\title{
Osler-Weber-Rendu sendromu: Bir olgu sunumu
}

\author{
Osler-Weber-Rendu syndrome: A case report \\ Okan Kızılyel, Mahmut Sami Metin*, Ömer Faruk Elmas, Necmettin Akdeniz, \\ Adem Karaman
}

Deri ve Zührevi Hastalıkları Ana Bilim Dalı (Dr. O. Kızılyel, Dr. M. S. Metin, Dr. Ö. F. Elmas, Prof. Dr. N. Akdeniz), Radyoloji Anabilim Dalı (Yrd. Doç. Dr. A. Karaman), Atatürk Üniversitesi Tıp Fakültesi, TR-25240 Erzurum

Özet

Osler-Weber-Rendu sendromu [Herediter Hemorajik Telenjiektazi] deri ve mukozalarda telenjiektaziler ve iç organlarda arteriyovenöz malformasyonlar ile karakterize otozomal dominant geçiş gösteren bir hastalıktır. Dudak, dil, damak, kulak, nazal mukoza, palmoplantar bölge ve tırnak yataklarında yerleşim gösterebilen telenjiektaziler hastalığın tipik bulgusudur. İç organ tutulumu olan hastalıkta pulmoner arteriovenöz malformasyon sıktır. Olgumuz dudağında ve yüzün sağ yarısında hemanjiom, oral mukozada telenjiektaziler ve sol akciğer alt lobunda arteriyovenöz malformasyonu olan 34 yaşında kadın hastaydı. Osler-Weber-Rendu sendromu tanısı konuldu. Hastalığının nadir görülmesi ve akciğerinde eşlik eden arteriyovenöz malformasyonu bulunması nedeniyle olgumuzu sunmayı uygun gördük.

Anahtar sözcükler: Herediter hemorajik telenjiektazi, Osler-Weber-Rendu sendromu, pulmoner arteriyovenöz malformasyon

\begin{abstract}
Osler-Weber-Rendu (Hereditary Hemorrhagic Telangiectasia) is an autosomal dominant disease characterized by telangiectasia on mucosa and skin and arteriovenous malformations in visceral organs. Telangiectasia on lips, tongue, ear, nasal mucosa, palmoplantar region and nail beds are typical findings in the disease. Visceral arteriovenous malformations are common in patients who have visceral involvements. Our case was 34 years old woman presented with hemangioma on her right side of face and lips, telangiectasia on oral mucosa and arteriovenous malformation in her lower lobe of left lung. Diagnosis was Osler-Weber-Rendu disease. We decided to report this case because it is rarely seen and arteriovenous malformation was present in the lung of the patient.
\end{abstract}

Keywords: Osler-Weber-Rendu syndrome, hereditary hemorrhagic Telangiectasia, pulmonary arteriovenous malformation

Geliş tarihi/Received: 22 Ekim 2013; Kabul tarihi/Accepted: 20 Ocak 2014

\section{*İletişim adresi:}

Dr. Mahmut Sami Metin, Deri ve Zührevi Hastalıkları Ana Bilim Dalı, Atatürk Üniversitesi Yakutiye Araştırma Hastanesi, TR-25240 Erzurum. E-posta: drmsamimetin@ gmail.com

Giriş

Osler-Weber-Rendu [OWR] sendromu tekrarlayan epistaksis, mukokutanöz telanjiektaziler ve birçok organda arteriyovenöz malformasyonlar ile seyreden otozomal dominant kalıtılan nadir görülen bir hastalıktır [1]. Hastalığın görülme sıklığı 1:5000 ile 1:10000 arasında değişmektedir [2]. Akciğer, karaciğer, gastrointestinal trakt ve beyin başta olmak üzere birçok organda arteriyovenöz malformasyonlar görülebilir [3]. OWR sendromu nadir görüldügü ve olgumuzda akciğerde arteriyovenöz malformasyon olduğu için bu olguyu sunmayı uygun gördük. 


\section{Olgu sunumu}

Olgumuz yüzün sağ yarısında ve üst dudağın sağ tarafında kızarıklık ve şişlik şikayeti ile polikliniğimize başvuran 34 yaşında kadın hastaydı. Hastanın yüzündeki kızarıklık ve dudağındaki şişlik son 2 yıldır varken son bir yıldır belirginleşmiş. Hastanın öyküsünden, çok sık olmasada burun kanamaları olduğu öğrenildi. Hastanın fizik muayenesinde yüzün sağ yarısında $3 \times 5 \mathrm{~cm}$ çapında kırmızımsı renkte, sağ burun kanadında $1 \times 1 \mathrm{~cm}$ çapında ve dudağın sağ üst kısmında $2 \times 3 \mathrm{~cm}$ çapında asimetriye neden olan hemanjiom ve oral mukazada özellikle yumuşak damakta belirgin telenjiektaziler mevcuttu (Resim 1a, 1b). Rutin laboratuvar tetkiklerinde anemi dışında anormallik saptanmadı. Laboratuvar tetkiklerinde; RBC $4,02 \times 10^{6} / \mu \mathrm{L}$ [Referans Aralığ1 (RA) $\left.=4,38-5,77 \quad \mathrm{X} 10^{6} / \mu \mathrm{L}\right]$, Hemoglobin $10.2 \mathrm{~g} / \mathrm{dL}$ (RA=13,6-17,2 g/dL), Hematokrit \%31,3 (RA=\%39,5-50,3), MCV 77,8/fL (RA=80,7-95,5/fL), MCH 25,3 pg (RA=27,2-35,6pg) MCHC 32,6 g/dL $(\mathrm{RA}=32,7-35,6)$ tespit edildi. Diğer rutin tetkiklerde anormallik yoktu. Bilgisayarlı toraks tomografide, parankim penceresinde sol akciğer alt lob lateral bazal segmentte pulmoner vasküler yapılar komşuluğunda pulmoner arterio-venöz malformasyon (PAVM) lehine değerlendirilen 8x6 mm ebatlı noduler lezyon tespit edildi (Resim 2). Hastaya pulmoner anjiyografi önerildi fakat hasta kabul etmedi. Ekstremitelerine yönelik renkli doppler ultrasonografi yapıldı, sonuç doğal olarak değerlendirildi. Transtorasik ekokardiyografisi doğal olarak değerlendirildi. Kolonoskopide patoloji saptanmadi. Gastroskopide mide mukozası eritemli olarak değerlendirildi, kanama odağı veya taze kan yoktu. Hasta bu bulgular ile OWR sendromu olarak değerlendirildi. Hastaya, şikayetlerine yönelik olarak, burun kanamaları hafif olduğu ve çabuk durduğu için konservatif yöntemler önerilirken, yüzündeki hemanjiom yapıları için lazer tedavisi önerildi.

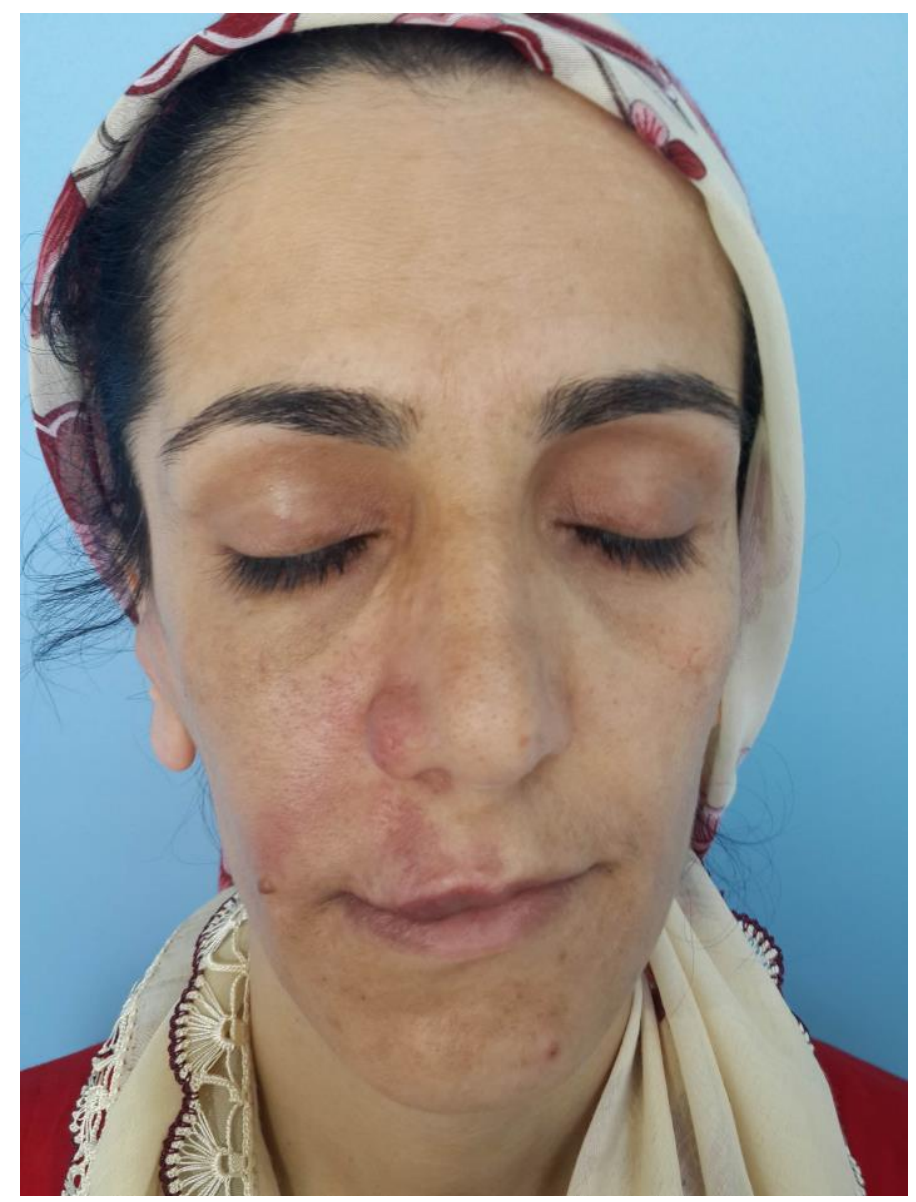

Resim 1a. Yüzün sağ yarısında $3 \times 5 \mathrm{~cm}$ çapında kırmızımsı renkte, sağ burun kanadında 1x1 cm çapında ve dudağın sağ üst kısmında $2 \times 3 \mathrm{~cm}$ çapında asimetriye neden olan hemanjiom. 


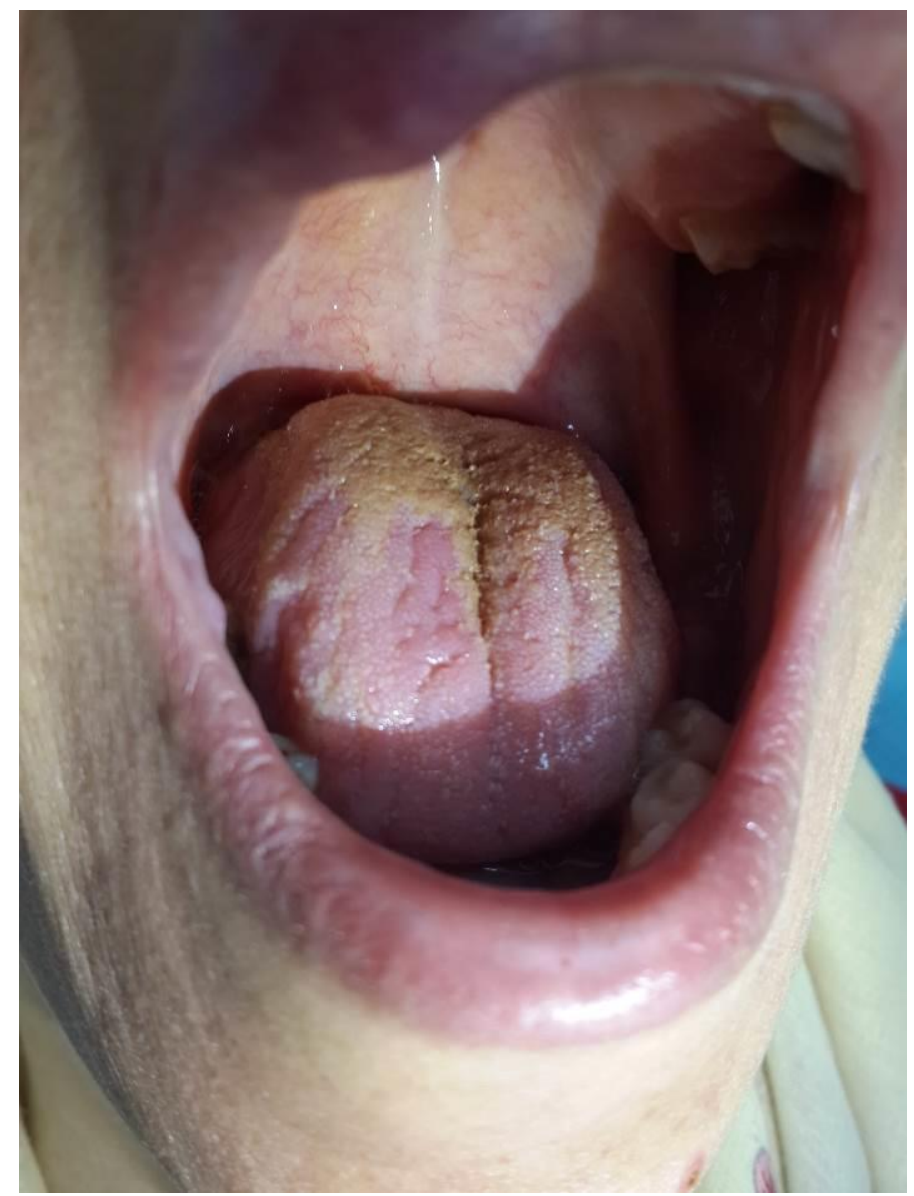

Resim 1b. Oral mukazada özellikle yumuşak damakta belirgin telenjiektazilerle birlikte paslı dil.

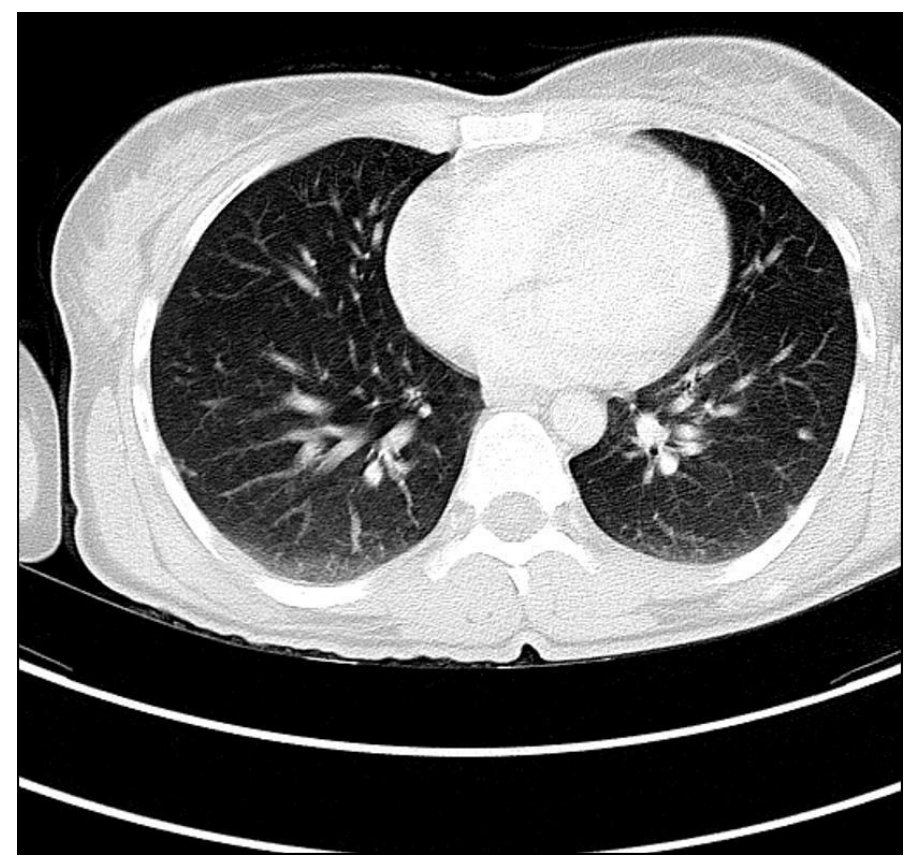

Resim 2. Bilgisayarlı toraks tomografisinde, parankim penceresinde sol akciğer alt lob lateral bazal segmentte pulmoner vasküler yapılar komşuluğunda pulmoner arterio-venöz malformasyon (PAVM) lehine değerlendirilen $8 \times 6$ mm ebatlı nodüler lezyon. 


\section{Tartışma}

OWR sendromu ilk dönemlerde çok sayıda nevus ve epistaksisin eşlik ettiği hemofili olarak tanımlanmıştır [4]. Daha sonra sırasıyla Rendu, Osler ve Weber tarafindan ailevi telenjiektazi ve mukozal kanamalar şeklinde tekrar tanımlanmıştır. Etiyolojisinde genetik faktörler suçlanmıştır. 9. kromozomdaki endoglin ve 12. kromozomdaki aktivin reseptör benzeri kinaz-1 genleri üzerinde durulmaktadır. Bu genler vasküler gelişim ve onarımdan sorumlu genlerdir [1]. Histopatolojik incelemede submukozal alanda dilate ve endoteli sağlam vasküler yapılar görülür. Vasküler duvardaki elastik liflerde kayıp ve perivasküler lenfosit infiltrasyonu görülebilir [5]. Klinikte tutulum yerine göre bulgular verir. En sık karşılaşılan bulgu mukokutanöz kanamalara yol açan telanjiektazi iken, ikinci en sık bulgu iç organlarda görülen arteriyovenöz malformasyonlardır [3]. Telenjiektaziler genellikle yüz, dudak, dil, oral mukoza, diş etleri, konjuktiva ve parmaklarda görülür. Telenjiektazilere bağlı kanamalar sıklıkla görülür [6]. Tanıda Curaçao tanı kriterleri kullanılır. 4 kriter mevcuttur. Bunlar; epistaksis, telenjiektazi (dudak, oral mukozada, burun ve parmaklarda), viseral lezyonlar (gastrointestinal telenjiektazi ve diğer organlarda arteriyovenöz malformasyonlar) ve aile öyküsünün (birinci derece akrabalarda OWR sendromu) bulunmasıdır. 2 kriter varsa şüpheli, 3 veya 4 kriter var ise kesin OWR tanısı konulur [7]. Bizim olgumuz oral mukozada telanjiektazi, yüzde hemanjiom, akciğerde arteriyovenöz malformasyon ve burun kanamaları olması ile tanı kriterlerini sağlamaktadır. OWR sendromunda tedavi tutulum yerine göre farklılıklar gösterir. Hastaların \%90'inda tekrarlayan burun kanamaları, \%10-33'unda sindirim sistemi kanamaları ve \%5-10'unda beyinde arteriyovenöz malformasyonlar görülebilir. En sık görülen bulgu epistaksistir. Epistaksis bazen anemiye sebep olabilecek kadar tekrarlayıc1 olabilir. Hastamızda da demir eksikliği anemisi mevcuttu. Hasta burun kanamalarından çok şikayetçi olmasa da epistaksise bağlı anemi gelişmiş olabilir. Epistaksisin tedavisinde tampon, antifibrinolitikler, östrojen, progesteron, lazer tedavisi, cerrahi ya da embolizasyon kullanılabilir [6, 8]. Hastamız kanama olduğunda tampon uyguladığını ifade etmişti. Gastrointestinal tutulum hastaların \%10-15'inde görülür. Hastalarda akut ya da kronik kanama ve anemi görülür. Kanamalar genellikle 30 yaşından sonra görülür. Endoskopide telenjiektaziler görülebilir [9]. Bizim hastamızda endoskopide patoloji saptanmamıştır. Kanamaya sekonder gelişen anemilerde demir desteği verilir. Akciğerdeki arteriyovenöz malformasyonlar gebelikte büyüyebilir. Asemptomatik olabildiği gibi dispne, egzersiz intoleransı ve siyanoz şeklinde bulgu verebilir [2]. Bizim olgumuzda akciğerdeki arteriyovenöz malformasyon asemptomatikti. Akciğerdeki arteriyovenöz malformasyonu sağ-sol şantına ve beyin apsesine neden olabilir. Vasküler kaynaklı trombüsler şant aracılığıyla beyne emboli atabilir. Bu paradoksal emboli olarak tanımlanır. Hastaların \%10-15'inde beyinde arteriyovenöz malformasyon görülebilir ve varlığı manyetik rezonans görüntüleme ile tespit edilebilir [10]. Akciğer tutulumu olan hastalarda yaşam boyunca inme sıklığı \%30 ve beyin apsesi sıklığ $\%$ 5-9 olarak bilinmektedir. Akciğer tutulumunda tanıda akciğer grafisi, ekokardiyografi, bilgisayarlı tomografi ve anjiografi kullanılabilir Akciğer tutulumunda cerrahi rezeksiyon ve embolizasyon kullanılır [11]. Hastaların \%70'inde karaciğerde arteriyovenöz malformasyon görülebilir. Genellikle asemptomatik seyrederken bazı hastalarda konjestif kalp yetmezliği, portal hipertansiyon ve nadiren karaciğer yetmezliği gelişebilir [12, 13].

Sonuç olarak; OWR sendromu çok sayıda klinik bulgular ile seyreden vasküler bir hastalıktır. Tanıda geç kalındığında mortalite ve morbiditiye sebep olabilen kanamalar başta olmak üzere çeşitli komplikasyonlara neden olabilir. Erken tanı ve tedavi ile bu komplikasyonlar önlenebilir.

\section{Kaynaklar}

1. Plauchu H, de Chadarévian JP, Bideau A, Robert JM. Age-related clinical profile of hereditary hemorrhagic telangiectasia in an epidemiologically recruited population. Am J Med Genet 1989; 32: 291-7.

2. Sharathkumar AA1, Shapiro A. Hereditary haemorrhagic telangiectasia. Haemophilia 2008; 14: 1269-80. 
3. Ergül Y, Nişli K, Dindar A. Osler-Weber-Rendu sendromu ile ilişkili pulmoner arteriyovenöz malformasyon. Türk Ped Arş 2011; 46: 264-6.

4. Grand'Maison A. Hereditary hemorrhagic telangiectasia. CMAJ 2009; 180: 8335.

5. Braverman IM, Keh A, Jacobson BS. Ultrastructure and three-dimensional organization of the telangiectases of hereditary hemorrhagic telangiectasia. J Invest Dermatol 1990; 95: 422-7.

6. Nanda S, Bhatt SP. Hereditary hemorrhagic telangiectasia: epistaxis and hemoptysis. CMAJ 2009; 180: 838.

7. Shovlin CL, Guttmacher AE, Buscarini E, Faughnan ME, Hyland RH, Westermann CJ, Kjeldsen AD, Plauchu H. Diagnostic criteria for hereditary hemorrhagic telangiectasia (Rendu-Osler-Weber syndrome). Am J Med Genet 2000; 91: 66-7.

8. Kamiński B, Błochowiak K, Olek-Hrab K, Sokalski J, Witmanowski H. Hereditary haemorrhagic telangiectasia in a patient taking anticoagulant drugs who has sustained facial trauma. Postepy Dermatol Alergol 2013; 30: 199-202.

9. Irani F, Kasmani R. Hereditary hemorrhagic telangiectasia: fatigue and dyspnea. CMAJ 2009; 180: 839.

10. Manawadu D, Vethanayagam D, Ahmed SN. Hereditary hemorrhagic telangiectasia: transient ischemic attacks. CMAJ 2009; 180: 836-7.

11. Cottin V, Plauchu H, Bayle JY, Barthelet M, Revel D, Cordier JF. Pulmonary arteriovenous malformations in patients with hereditary hemorrhagic telangiectasia. Am J Respir Crit Care Med 2004; 169: 994-1000.

12. Memeo M, Stabile Ianora AA, Scardapane A, Buonamico P, Sabbà C, Angelelli G. Hepatic involvement in hereditary hemorrhagic telangiectasia: CT findings. Abdom Imaging 2004; 29: 211-20.

13. Seethala S, Shah H, Knollmann F, Ramani R, Němec J. Radiofrequency ablation of post-incisional atrial flutter and high-output heart failure in a patient with interrupted inferior vena cava and hereditary hemorrhagic telangiectasia. Hellenic J Cardiol 2013; 54: 474-9. 